\title{
VEHICLE-RELATED CRIME AND THE GENDER GAP
}

\section{Dr Claire Corbett}

School of Social Sciences and Law

Brunel University

Uxbridge

Middlesex

UB8 3PH

\section{Email: Claire.Corbett@brunel.ac.uk}

This was published as follows:

Corbett, C. (2007) 'Vehicle-related crime and the gender gap'. Psychology, Crime and Law. 13(3), 245-263. Routledge: London.

http://dx.doi.org/10.1080/10683160600822022 


\section{ABSTRACT}

Although vehicle-related offending and traffic offenders are of interest to some behavioural psychologists, criminologists have been less enthused and their concern has been largely restricted to crime to vehicles rather than crime by drivers or wider society. Both disciplines have, however, largely ignored the contribution of women to vehicle-related offending statistics, mirroring the pattern seen in regard to mainstream offending. This paper attempts to plug the gap by considering the relative contributions of men and women to motoring conviction data and self-report offending studies. To some extent it also does this by age, where evidence for a 'ladette' style of driving among young women is examined from the conviction data. In general, a gender gap similar to that in mainstream crime is noted, and key theoretical explanations that could account for this are assembled. Implications for improving road safety and research are then considered given this gap and emerging support for the non-homogeneity of female driving styles.

Key words: vehicle-related offending; gender differences; age differences; enforcement; conviction data; self-report studies. 


\section{INTRODUCTION}

With almost every two European adults owning a car between them (European Commission, 2004, Table 3.6.1) and over half the European population holding driver licences (CIECA, 1998), Western lives are securely embedded in car culture. Yet despite the near-ubiquity of cars in our lives, criminology as a discipline has been slow to show interest in exploring the many criminal activities linked with the car except theft offences. Explanations for this are unclear, but the fact remains that more people are killed and injured in road collisions than are killed and injured elsewhere. Thus in 2004 in Britain there were 3,508 road fatalities (Dept. for Transport, 2004, Table 8.1) and 853 homicides (Dodd et al, 2004, 78), and in Ireland over the last 30 years there have been almost six times as many road fatalities as deaths arising from political violence there (AA Motoring Trust, 2005). At least a fair proportion of road injury collisions are linked with breaches of the traffic laws (e.g. Forsyth and Silcock, 1987; Junger West and Timman, 2001). Moreover, drivers who offend more, and more seriously, tend to have higher crash rates (e.g. Stradling and Parker, 2001; Junger, op. cit.) and there are links between vehicle-related and mainstream offending (e.g. Rose, 2000; Broughton, 2006). If these were not sufficient grounds to justify more criminological concern, then the harm and distress caused to victims and the bereaved is no less when resulting from a road collision than from off-road incidents, and may in some senses be worse (RoadPeace, 2002).

In 1975/6 when it first became possible to assess the distribution of full driving licence holders, the ratio of male to female licence holders in Britain was $2.2: 1$ (Dept. for Transport, 2004, Table 9.16). In 2003 the ratio had reduced to $1.3: 1$ (ibid) and the difference could disappear during the next decade. Among females, $45 \%$ now class themselves as a 'main driver' in their household compared with $35 \% 10$ years ago (National Travel Survey Unit, 2005, 39), and most growth in road traffic during the 1990s is attributable to the greater distance travelled by women drivers in that period (ibid, 37). Surveys suggest that over 3 out of 10 used car purchases are made by females, as are 4 out of 10 new car purchases (SMMT, 1999, 7). Further, women may soon comprise half the driver population, holding $44 \%$ of all full driver licences in 2003 (from data supplied by the DVLA in 2005). In other words, roads are no longer the preserve mainly of male drivers; women drivers have a significant presence there and their effect on offending patterns now deserve scrutiny. 
Behavioural psychologists have shown some specific interest in women drivers who offend, but this is a neglected topic among criminologists, reflecting the general lack of attention given by them to women's contribution to mainstream crime. In this regard, it has long been known that females, who comprise $51 \%$ of the British national population (National Statistics Online, 2005) play a minor role in the criminal statistics for court convictions (Prime et al, 2001; Johnson et al, 2001, Table 4) and report less offending than men in crime surveys (Budd, Sharp and Mayhew, 2005, 1718; Flood-Page et al, 2000). Yet their lower level of apparent involvement hardly appears a sound justification to have given them scant attention (e.g. Heidensohn, 2002, 516-517).

Indeed, as more women gain their driver licences, it is timely to start plugging the gap by considering the relative contributions of men and women to vehicle-related crime, and whether similar patterns pertain on the road in regard to their reported and recorded offending as off it, and the implications of these patterns for improving road safety. This will be attempted by referring to relevant research studies and by some secondary analysis of published statistical data. Readers should note that in this paper 'traffic crime', 'motoring offences' and 'vehicle-related crime' are used synonymously and to refer to moving motoring offences, document, construction and use offences and to theft offences, though vehicle-related offending can be cast more widely (e.g. Corbett, 2003).

\section{COURT CONVICTION DATA FOR TRAFFIC OFFENDING AMONG WOMEN}

Table 1 shows the proportion of females found guilty in the courts of various vehiclerelated offences at different points over the last 15 years. Despite the vagaries of conviction data that are dependent on local and national police enforcement policies and practices, and the growing use of fixed penalty notices for some offences over that period particularly for speed limit offences, a fairly stable picture results.

\section{Table 1 about here}

By deduction it is noted that the vast bulk of court convictions were against male drivers, although the proportion of female convictions gradually increased overall during this time from $7 \%$ in 1988 to $12 \%$ in 2003 . However, women now comprise a 
greater slice of the total driver licence holder population and their share has increased from $38 \%$ to $44 \%$ over this period, at the same time as the total number of licence holders has grown from 27.5 million to 33.8 million. So part of the increase in female convictions may be accounted for by the proportion of women holding driver licences growing quicker than that of men over the period, meaning that there were correspondingly more women drivers around to get caught in 2003. In addition, women now drive further, covering on average almost $50 \%$ more miles at the end of 1990s as at the beginning (National Travel Survey Unit, 2005, 43). This additional exposure could raise the average woman driver's detection risk for traffic offending where it occurs.

The next interesting point is that the split between male and female convictions for these motoring offences is quite similar to the split between the sexes in regard to mainstream offending. Recorded statistics for 2003 show that $77 \%$ offenders convicted of all non-motoring offences were male (derived from Tables S1.1(A) and S2.1(A), Home Office, 2005), compared with $88 \%$ convicted of all motoring offences for 2003 as shown in Table 1. This is interesting because much vehicle-related crime is said to be qualitatively different to mainstream crime in that intention to break a law is often lacking, and rather more vehicle-related crime than mainstream crime concerns an oversight, fleeting carelessness or failure to act (such as a failure to signal change of direction) rather than the deliberate commission of an act. Despite these differences, a strong gender division in court convictions is apparent on and off the road as noted, with men responsible for the large bulk.

This does not necessarily mean, however, that the same people are responsible for driving offences and mainstream offences, but the theory espoused by Tillman and Hobbs in 1949 that 'man (sic) drives as he lives' has received considerable support, most notably by Broughton (2006) in a large statistical study. Other support is exemplified by Rose (2000) who found that convicted drink-drivers were twice as likely, and disqualified or dangerous drivers four times as likely, as the general population to have a criminal record for mainstream offending.

Returning to Table 1, and having noted that women drivers are convicted far less than men and that this pattern has remained relatively stable over the last 15 years, it is not, 
of course, suggested that women's driving styles are homogenous. Indeed, earlier research suggests that some women have distinctive styles. For instance, Reason et al (1990) reported that around $10 \%$ of female drivers aged 36 or more were high violators and Simon and Corbett (1996) found that some career women admitted to similar levels of speeding and other road offending as men. In this context too, it is relevant to consider current claims about the emergence of a 'ladette culture' among younger women such that increasing aggression on the road and the adoption of a deviant masculine driving style, including drink-driving, is becoming more evident among them (e.g. Daily Mail, 17.3.05, 45; BBC News Magazine, 11.1.05; Guardian, 24.1.06, 8). To see whether there is any support for a 'ladette style' of driving, the next section will consider motoring conviction data (for all their vicissitudes) and conviction rates for young and older women in 1998 and 2003 and compare these to male rates.

There is, however, a caveat to this. As a relatively new phenomenon, the age range of supposed 'ladettes' has not been well defined other than their being young women. Motoring conviction and mainstream conviction data published by the Home Office (in Britain) are traditionally divided into those applying to under $21 \mathrm{~s}$ and $21+$ years, but to define 'young drivers' as under 21 would be an arbitrary distinction and they are often treated in the literature as spanning the 17-24 age group (e.g. Waller et al, 2001). In the tables that follow, therefore, it is possible that 'ladettes' - should they attract motoring convictions - could feature in both the under 21 and 21+ groups.

\section{A RECENT UPSURGE IN FEMALE TRAFFIC OFFENDING?}

\section{Table 2 about here.}

As a preface to Table 2, it is important to note that driving licence offences were the second most common category of motoring convictions arising at all courts in 2003 and very largely comprise offences committed by drivers not holding a full driving licence, such as driving while disqualified, with a provisional licence while unaccompanied, with no ' $L$ ' plates when required, or having never held a valid licence. Further, it is often the case that those driving without an appropriate licence also drive without valid insurance and perhaps in an unregistered vehicle, and such drivers can be convicted of any other motoring offence such as dangerous driving. Indeed, deriving a completely valid total number of convictions awarded against full 
driver licence holders cannot be determined currently from the recorded statistics kept. Given these difficulties, omitting all driver licence convictions was considered the best way to get closer to an accurate total of convictions made against full driver licence holders. The numbers of convictions and conviction rates with and without this adjustment are shown in Table 2.

Despite the large number of licence convictions recorded, the overall pattern produced by omitting them is almost the same. Because of this similarity, the discussion that follows will refer to the adjusted figures only, except in the one instance where the pattern differs. Thus Table 2 confirms that the overall rate of male motoring convictions was much higher than that for women in both 1998 and 2003. There were almost six convictions per 100 licensed male drivers to around one conviction per 100 licensed female drivers in both years. Moreover, this table confirms that by far the highest conviction rate was among men aged 17-20 years, and that this rate rose considerably between 1998 and 2003 from 33 to 44 convictions per 100 licensed young drivers. This is an extremely high rate, though it must be remembered that frequently several offences are charged to one driver from one incident, and some of these convictions could have arisen against drivers without full licences. Among men aged 21 and over there was also a slight rise across the time period, but their conviction rate was considerably lower at no more than five convictions per 100 drivers in both years.

Partly mirroring this, the conviction rate for young females was around three times higher than that for women aged 21 and over in both years, with an increase shown from 2.75 to 3.2 convictions per 100 young female drivers over that period. The conviction rate for older women rose minimally from 0.92 to 1.01 over the same period. On the face of it, therefore, no huge explosion in the female conviction rate is suggested over the five year span, though the situation seems rather different for young men.

The underlying picture in motoring conviction data between 1998 - 2003 The pattern of changes in numbers of convictions and licensed drivers in seen more clearly in Table 3, which throws light on the underlying picture. This shows that despite a $35 \%$ drop in numbers of young licensed male drivers over the five year 
period there was a $1 \%$ overall (adjusted) rise in convictions among them. So while there was a slight increase in convictions over that time, there was a far larger drop in young men available to commit them. Offence categories showing a disproportionate rise were dangerous driving $(+30 \%)$, driving after alcohol or drugs $(+16 \%)$, insurance and record-keeping offences $(+12 \%)$, and licence offences $(+35 \%)$. The latter category yielded the largest absolute rise of over 19,000 extra convictions, though would largely have been committed by those without full driver licences. Interestingly, speeding convictions (representing the worst breaches) reduced by 54\% among young men, suggesting a positive deterrent value of speed cameras.

\section{Table 3 about here.}

Among men aged 21 and over, a very slight (adjusted) decrease in convictions of $<1 \%$ was seen corresponding with a $2 \%$ increase in licensed drivers. Within this too, a drop in most kinds of offence categories was noted such as a $14 \%$ fall in speeding convictions, but dangerous driving was up 12\%, insurance offences up $13 \%$ and by 46,000 , and licence offences up by $26 \%$ and by 40,000 . So fewer convictions per older licensed male driver were seen over the five year period to 2003.

Among younger women, despite a 32\% drop in licensed drivers only a 13\% overall (adjusted) drop in convictions was seen over the period, that included a 40\% drop in speeding convictions. The biggest disproportionate rise emerged for drink driving $(+30 \%)$ with a considerate rise in licence convictions $(+19 \%)$. Although these are worrying increases especially for drink-driving and licence offences, viewed in terms of absolute numbers, female conviction rate changes still have a fairly minimal effect on the total compared with numbers of male convictions.

Among women aged 21 and over there was a 7\% rise in licensed drivers over the period and a $18 \%$ (adjusted) increase in motoring convictions. Despite the increase in women available to commit offences, there was a disproportionate conviction rate rise in most offences shown in Table 3, yet small numbers were occasionally involved so caution is needed. Particular offences showing large absolute rises were insurance and record-keeping offences up $29 \%$ and by 14,600 , speed limit offences up $27 \%$ and by 5,000 , and drink driving up $18 \%$ and by 1,500 . Licence offences showed the largest disproportionate rise - up $43 \%$ and by almost 7,000. These are concerning 
trends that deserve greater attention, especially as the increases in these offences appear to be more prominent among older women than older men.

Putting these findings together, it appears that overall there is some support for the 'ladette' thesis since despite a $6 \%$ increase in licensed female drivers over the five year period, there were far higher disproportionate rises among women under and over 21 years in dangerous driving $(+39 \%)$, drink and drug driving $(+19 \%)$, speed limit convictions $(+24 \%)$ and insurance and record-keeping convictions $(+25 \%)$. The largest absolute and disproportionate rise occurred for licence offences up 39\% and by over 7,000. Of course, these increases for females could be linked with greater enforcement activity rather than a rise in female criminality behind the wheel, especially for speed limit enforcement by speed cameras. Yet other than speeding, these offence types tend to come to light mainly in response to road collisions rather than proactive police patrols, that would suggest a real rise in offending among women rather than an apparent one.

In regard to overall male conviction patterns the picture differs according to whether unadjusted or adjusted rates are used, pointing up the salience of licence offences to male motoring conviction patterns. Using the preferred adjusted rate that omits licence offences to calculate the conviction rate, a slight adjusted fall of $<1 \%$ occurred over the five year period in contrast to a $1 \%$ increase in licensed male drivers. Disproportionate rises in dangerous driving (+ 18\%), insurance and record-keeping (+ $13 \%$ ) and licence convictions (29\%) were noted among male drivers overall and among under and over 21s separately, though a disproportionate rise in drink and drug driving was seen only among younger male drivers.

Thus while moderate support is lent to the 'ladette' thesis of a slightly increased conviction rate among women drivers - more so younger ones - in recent years, support for the continuance of a strong 'laddish' culture among men under 21 is clearly evident, with a much increased conviction rate seen among this group. By contrast, the conviction rate for men aged $21+$ barely changed. Overall, absolute numbers of male convictions far outweigh those for women, thus the pattern changes among women often relate to quite small numbers. Yet before it is concluded that men surpass women in regard to all types of traffic offending, it must be remembered 
that conviction data relate to the more serious motoring offences, and it could be that fixed penalty notices issued to women for the more minor but endorseable traffic offences (where penalty points are given) have grown disproportionately faster over the same period compared with those issued to men. However, investigation of such unpublished statistical data was outside the present remit.

Is there any link with binge drinking?

Given the rise in dangerous driving and drink and drug driving convictions among both men and women drivers between 1998 and 2003, a question emerges whether there is any link between these driving behaviours and reports of binge drinking among the young? A survey by ESPAD (2004) found that UK teenagers were the heaviest drinkers in Europe, and a nationally representative Home Office survey showed that $39 \%$ young women and $49 \%$ young men (aged 18-24 years) admitted binge drinking in the previous month (Matthews and Richardson, 2005). That survey throws some light on the influence of peer pressure and the social contexts of binge drinking but leaves room to explore any potential connection between this behaviour and the rise in drink driving, particularly among younger women. Thus in the current state of knowledge, the ladette phenomenon deserves immediate attention in its manifestations (if any) in traffic offending among young female drivers.

Demographic data changes between 1998 - 2003

Implicit in the above discussion are the numbers of full driver licence holders represented in each of the different age -gender categories, though numerical changes in them over the period under examination deserve explicit comment before moving on.

Specifically, Table 3 shows that over the five year period considered, there was a considerable drop in the number of fully-licensed drivers of both sexes under 21 years old. This is a general trend over time and causes speculated by the National Travel Survey Unit (2005: 39) include the possibility that young people are finding it more difficult to pass driving tests with the introduction of the theory test in Great Britain, that more young people are students who cannot afford cars; and that insurance costs are very high for drivers under 25 . 
While it would be expected that the under $21 \mathrm{~s}$ in 1998 would transfer over to the over 21 s in 2003, not all of these men are apparently doing so, begging the question 'why'? It could be that more men than women are falling out of the pool at the other end through death or not renewing their licences when reaching 70 , though superficially there is little support for this given that still $69 \%$ of men but only $27 \%$ of women aged over 70 held licences in 2002/3 (ibid: 38 ).

Alternatively, it might be that more females than males are entering the fully licensed driver ranks directly aged 21 years and over, perhaps finding the theory element of the new test tougher than men, which is delaying their entry at a younger age? Perhaps more likely is an explanation based on women's growing use of cars representing a means to reduce the risk of male crime and fear of it (London Research Centre, 1998; Maxwell, 2001), in which case it could be that the 'responsibilisation message' aimed at women is getting through. For instance, Radford and Stanko (1991) observe that women have long been exhorted by official bodies to remove themselves as targets from male predatory tendencies and not to act injudiciously at night by walking home alone and through darkened areas. While men do not attract social approbation for such actions, car usage for women neatly avoids this risk of victimisation and, importantly, the potential social censure of women that could accompany it should the worst happen. Thus the large upward shift of $7 \%$ over the five year period among licensed female drivers aged 21+ compared with the $32 \%$ drop among older male drivers could partly be explained by issues around the perceived safety of car usage among women.

Another possibility is that the far higher incidence of licence problems among young men indicates that their motivation to start driving is higher than that of young women at an earlier age, and that if disqualified from driving they are failing to regain their licences once 21 and over. Certainly, there is concern in this regard as Greenaway (2004 : 12) noted from DVLA figures that among the 72,000 young drivers who had had their licences revoked by November 2003 under the Road Traffic Act (New Drivers) 1995, less than half had by that time been re-tested. It could be therefore that part of the unexpected shortfall in licensed male drivers aged 21 and over could be a consequence of unlicensed driving among some of those who have been disqualified from driving. 
Whatever the reasons, these demographic changes by gender would seem to have policy relevance given that they may indicate future trends in the distribution of the driving population and possible underlying trends in unlicensed driving.

\section{SELF-REPORT AND OTHER STUDIES ON TRAFFIC OFFENDING BY GENDER DIFFERENCES}

Self-report surveys and interviews provide the other main source of data on gender differences in unlawful driving behaviour to complement conviction data. Surprisingly, in view of the amount of research conducted, few self-report studies have distinguished the relative unlawfulness of female and male drivers on the road, but the following findings have emerged.

Unauthorised taking and theft of vehicle offences:

Strictly speaking these are not motoring offences but property offences. They are included here as vehicle-related offences and because some recent survey data on their prevalence by gender exist to compare with conviction data. A key source comprises the 2003 Crime and Justice survey of a representative sample of 12,000 people between 18-65 years old in England and Wales living in private households (Budd, op. cit., 74). This showed that men were seven times more likely than women to report 'ever' having committed a vehicle-related theft offence (including attempts), with $10.8 \%$ men and $1.6 \%$ women admitting this. Men were eight times more likely to admit the same during the 'last 12 months'. To the author's knowledge there is no recent equivalent survey for younger people that asked similar questions. However, a nationwide Young People and Crime (YPAC) survey of a representative sample of around 2,500 young people aged 14-25 more than a decade before also confirms the picture of far greater male involvement (Graham and Bowling, 1995, Table 2.1, C1 and $\mathrm{C} 2$ ). Considering conviction and survey data together strongly reinforces the notion that women are far less interested in stealing vehicles for 'joyriding' or permanent deprivation, a finding that smaller-scale, more qualitative studies support. (e.g. Light, Nee and Ingham, 1993).

Licence and insurance offences: 
The YPAC survey of young people by Graham and Bowling (1995) just mentioned also provides evidence that driving without a valid licence or insurance is more attractive to men. They found that males between 14-25 were around three times more likely than females to admit such an offence 'ever' (30\% v 11\%) or 'in the last 12 months' (13\% v 5\%). Similarly, Knox et al (2003) used postal surveys, telephone and face-to-face interviews with various samples including provisional licence holders, disqualified drivers and the general public to find that a high proportion of those who admitted driving unlicensed were young and male, and that they were more likely than the rest to drive without insurance.

Dangerous and reckless driving:

Young men also owned up to more of this than young women in the YPAC (1995) survey, $21 \%$ men and $1 \%$ women admitting 'ever' engaging in it, and $8 \%$ men and $<1 \%$ women doing it 'in the last year', which supports the big difference noted between the sexes in the conviction data shown in Table 1.

Aggressive driving:

Although not a self-report study, Mizell (1997) constructed a US database of over 10,000 news, police and insurance reports of aggressive driving incidents defined as violent disputes where a driver or passenger intentionally injured, killed or tried to injure or kill another road user. This found that only 4\% perpetrators (where known) were female. At the milder end of 'road rage', where hand gestures, horn-honking, light flashing and verbal abuse are safer ways to express aggression than physical confrontation, gender differences are less marked though still significant in the expected direction (e.g. Leaseplan, 2001). Aberg and Rimmo (1998) and Blockley and Hartley (1995) also found in survey data that aggressive driving was greater among men and decreased with age for both sexes.

\section{Drink-driving:}

This is another offence less often found among and admitted by women. Large-scale roadside surveys conducted in ten British counties during 1988-1990 discovered that of breathalysed drivers over the blood-alcohol limit, 9 in 10 were men (Everest, Davies and Banks, 1990). In the same surveys, of those having drunk any alcohol before driving, $13 \%$ were men and $7 \%$ women. More recently, similar results 
showing gender differences in 'driving after alcohol' and 'driving thinking they might have been over the limit' arose in a survey of a nationally representative sample of Scottish drivers (Anderson and Ingram, 2001). The YPAC (1995) survey (as reported in Rose, 2000, 14-15) showed $17 \%$ young men and $6 \%$ young women admitting 'ever' driving knowing they were over the legal limit, 10\% men and 3\% women admitting doing so in the 'last 12 months'. Internationally, results are similar. Caetano and Clark (2000) found in an US nationwide household survey that irrespective of ethnicity (white, black or Hispanic) roughly four times as many men as women admitted 'ever being arrested for driving under the influence of alcohol' or being arrest for this 'in the last 12 months'. A recent national roadside survey in Belgium to estimate the proportion of drink drivers showed that women were far less likely than men to have an illegal blood-alcohol level when tested (Vanlaar, 2005, 393). Women's odds for drink driving were decreased by $75 \%$ compared to men.

\section{Drug-driving:}

The incidence of this has risen to greater prominence during the 1990s, with road crash fatality figures suggesting a six-fold increase over the decade, and cannabis seeming to be the drug of preference among such drivers (Tunbridge, Keigan and James, 2001). Although the presence of cannabis does not prove that impairment has occurred or was a causal crash factor in these accidents, driving while drug-impaired is an offence and is likely to raise the risk of a crash generally. To date, few surveys have noted sex differences among drivers in reported use of drugs before driving. One household survey which did, of a nationally representative sample of 1,008 17-39 year olds in Scotland, showed that males were around two and a half times as likely as females to have 'ever' driven under the influence of drugs or to have done so 'in the last 12 months' (Ingram, Lancaster and Hope, 2001). For example, 13\% males and $5 \%$ females admitted 'ever' having done so.

\section{Speeding:}

Sex differences are often noted in regard to self-reported speeding and speeding convictions, particularly at higher levels of excess speed. Stradling et al's (2003: 91) study of a large sample of Scottish drivers showed that significantly higher proportions of males to females reported exceeding speed limits on road types with higher speed limits, while the proportions did not differ on slower roads. The same 
research showed that proportions reporting speeding decreased with age among both men and women, with more male speeders in each of four age bands between 20-59 years (ibid). Corresponding with more speed limit compliance in general by women, a 2003 survey by Corbett and Caramlau (2006) showed that significantly more female drivers reported complying with speed cameras than men.

Other traffic offences:

To complete the picture of self-reported offending by gender, a series of seven large surveys conducted for a study on the effects of speed cameras by Corbett and Simon (1999) asked drivers how often they committed a range of traffic offences other than speeding. In all of the seven surveys, women drivers reported significantly lower levels of overtaking on hatched white lines, overtaking on the inside and pulling out from side roads without giving way. In six of the surveys, women were significantly more likely to report using indicators correctly and less likely to park on single yellow lines. In two surveys women were less likely than men to report driving through red lights and driving when over the blood-alcohol limit. The same study showed that women were likely to report significantly fewer penalty points on their driving licences than men (Corbett, 2003, 119).

The general pattern that women are less inclined deliberately to breach traffic laws is also confirmed by research conducted by Stradling and colleagues (e.g. Reason, op. cit.; Parker et al, 1995; Stradling and Parker, 2001). A general and recurring finding in their extensive studies is that male drivers are twice as likely to be 'high violators' as female drivers (about 40\% v 20\%), which includes intentional 'bad acts' that are mostly but not necessarily breaches of the traffic laws. These violations include driving actions such as failing to stop at red traffic lights, driving too close to the vehicle in front (tailgating), unofficially racing other drivers, overtaking on the inside, driving when over the legal blood-alcohol limit, and disregarding speed limits late at night or very early in the morning.

In all, from existing data sources it is concluded that female drivers break the various motoring laws less frequently and less seriously than male drivers whether conviction or self-report data are examined, and that younger male drivers and to a lesser extent younger female drivers tend to comply less than older drivers. This pattern of 
offending on the road largely reflects that for offending off it in terms of gender and age proclivities.

\section{GENDER DIFFERENCES IN CRASH INVOLVEMENT}

Not only are there gender differences in the amount of traffic offending, but also women and men vary in their levels of crash involvement. Maycock et al (1991) showed in a national accident dataset that fatality risk for drivers was higher for men where men and women were matched for mileage travelled, suggesting overall that when they are involved, women tend to have less serious crashes than men. Using a similar dataset and controlling for mileage, McKenna et al (1998: 11) showed that in five types of common injury crash scenarios men's crash involvement was higher generally, and that men had a higher proportion of crashes on bends, while overtaking and during hours of darkness, while women had more accidents at junctions. Back in 1977, Storie found women had more accidents connected with perceptual and judgmental errors. This indicates that high speeds add to the risk for men while making errors in perceptual judgement is a key risk factor for women. McKenna also found that the sex difference in crash proneness was more evident among younger drivers than older ones, which is a finding shared by other studies (Evans, 1991; Waller et al, 2001; Parker et al, 1995).

\section{EXPLANATIONS FOR GENDER DIFFERENCES IN OFFENDING ON THE ROAD}

So what explains this gender gap? Unsurprisingly, theorising these individual differences in unlawful driving behaviour has not been a top priority for criminologists, given that theorising the gender gap in mainstream offending has long been a neglected concern except among feminist theorists (e.g. Heidensohn, 2002). In the brief review that follows, key explanations put forward by traffic psychologists, criminologists and inter-disciplinary researchers are given.

Biological explanations:

Evolutionary psychology provides a main explanation on and off the road for greater male tendencies to enjoy risk-taking (e.g. McKenna et al, 1998 - on the road; 
Zuckerman, Eysenck and Eysenck, 1978 - off the road), to seek thrills (West, Elander and French, 1993 - on the road; Martin and Parker, 1995 - off the road), and to display aggression (e.g. Mizell, 1997 - on the road; Wilson and Herrnstein, 1985, 117-121 off the road). This perspective, espoused by Marsh (2004), says that men's brains have been hormonally and neuro-chemically programmed as hunter-gatherers since Stone Age days, which manifests in higher accident and insurance claims and higher conviction rates for dangerous driving offences among men. Women, by contrast, have been 'hard-wired' for child-rearing, communication and social skills which renders them less likely to exhibit aggressive or dangerous driving behaviours. Similarly, the literature on biological differences frequently notes dissimilarities between the sexes in spatial skills (Voyer, Voyer and Bryden, 1995) and given males' higher levels of aggression, this could account for the greater willingness among males to 'close follow', to 'cut in', to overtake dangerously and to exceed speed limits. In this regard, Stradling and Parker (2001) noted the greater tendency of high violators to drive in this way, and males were twice as likely as females to be high violators in their research. Men were more likely to close follow, exceed speeds limits and to overtake dangerously in research by McKenna et al (1998).

Likewise, the greater propensity of men to be thrill-seeking could help account for the mainly male involvement in 'joyriding' (Budd et al, 2005) and the reported thrill of the chase by the police (Light et al, 1993; see Corbett, 2003, 54-59, for more explanations for joy-riding).

Socio-cultural explanations;

Despite the biological argument, any tendencies to act will be shaped by our social environment and these are likely to be woven around normative prescriptions of appropriate gender and culture specific behaviour. Driving behaviour will be no exception to such influences. Messerschmidt (1993) notes how normative expressions of masculinity include competitiveness, coolness, assertiveness and willingness to take risks, which traits were amply shown in research by Gusfield et al (1980). This ethnographic study of drink-driving behaviour conducted in several Californian bars showed how being seen as competent to handle driving after drinking in the eyes of fellow male drinkers was crucial to masculine self-image. It was failure to drive after drinking that needed explanation rather than the expected act of doing so, which 
finding highlighted some of the culturally embedded aspects to male risk-taking applicable to driving.

Socio-cultural meanings of driving illustrate that men's use of vehicles is more expressive than women's, with intrinsic pleasure in the act of driving for its own sake more important (Marsh and Collett, 1986), which in turn could facilitate lawbreaking. For instance, driving affords opportunities for drivers to impress others with their skills and to show off their vehicle, to feel excitement and to project an idealised self-image, which are features more frequently associated with male driving (ibid, especially pp 25-62, 115) and which arguably could lead to breaches of the traffic laws. Conversely, women's usage tends to be more functional, with several purposes often being achieved in one journey, such as the need to juggle shopping, 'escort duties' and work schedules (Maxwell, 2001; London Research Centre, 1998).

It now appears that the underpinning complexity of some women's lifestyles such as indicated above, may lead to undesirable behaviours emerging in women's driving. A large-scale Australian survey by Dobson et al (1999) found that among some midaged women (especially those having children and working long hours in professional occupations) feeling rushed, pressured or too busy, working more than 40 hours per week, having a higher habitual alcohol consumption, or having lower life satisfaction scores were associated with poorer driving behaviour including speeding and other traffic breaches, and higher levels of lapses and errors on the road. Such findings chime with Bost's (2001) evidence for 'hurried woman syndrome' that results from women, typically aged 25-55 and often mothers, who live with the chronic stress of trying to fulfil many roles for many people like managing demanding paid or voluntary jobs, maintaining a home and bringing up children and facilitating their activities. Bost noted that such lifestyles cause fatigue, stress, self-doubt, overeating, lack of energy and eventual depression that all need treatment.

Clearly, more research to explore the links between pressured lifestyles and traffic offending behaviour among mid-age women would be salient, especially since such women are not usually constructed as 'problem drivers'. Certainly, a relatively high proportion (48\%) of female company car drivers (presumably including mid-age women) admitted behaving aggressively in a survey for Leaseplan (2001) indicating 
that women who drive as part of their job can experience 'road rage' almost as much as male company car drivers $(53 \%)$.

\section{Control explanations:}

Within mainstream criminology, socio-cultural explanations of behaviour have largely surfaced in the guise of control theories, and as Heidensohn $(2002,522)$ points out, 'gender-specific social control is .... a widely-cited component of most efforts to discuss women and crime'. She and others (Heidensohn, 1996; Hagan, Simpson and Gillis, 1979) have noted the informal pressures and sanctions placed on women by family to conform to appropriate gender prescribed behaviours that discourage deviance and apply far less to men. However, despite some support mainly from studies of juveniles that stronger social controls on women account for their greater commitment to conformity (Hagan et al, 1979; Junger, Terlouw and van der Heijden, 1995), other research support has been mixed (e.g. Mawby 1981).

Explanations centred around control might be applied to the gender gap in road traffic offending, but few direct attempts have so far been made. One such by Junger et al (1995) found interrelationships between traffic accident involvement, delinquency measures and social control measures, and that Dutch females aged 12-24 had fewer accidents, lower delinquency involvement and more social controls than similarly aged males; another attempt by Keane, Maxim and Teevan (1993) applied elements of self-control, as in Gottfreson and Hirschi's (1990) general theory of crime, to understand drink-driving behaviour among a Canadian roadside sample.

In all, explanations for gender differences in traffic offending have focused mainly on biological propensities and socio-cultural influences, which effects will be intertwined. More work to explore the gender gap could repay attention, though as noted earlier, women's and men's driving styles are not assumed to be without overlap and a better understanding especially of those women who tend to adopt male driving styles (e.g. Reason et al, 1990; Simon and Corbett, 1996) would also be useful and interesting.

\section{IMPLICATIONS OF THE GENDER GAP}


To sum up, the evidence reviewed strongly suggests that women break fewer laws of the road whether conviction data or self-reports are used. They also rate traffic offences more seriously than men do (e.g. Stradling et al, 2003, 104) and have fewer crashes on the road. Despite the large absolute gender differences in conviction data there are indications from this paper that women are offending more seriously and more frequently than before, and should these results have wider application there are several implications.

Implications for road safety:

The first is that in parallel with mainstream offending the biggest challenge to the control of traffic crime is represented by male behaviour patterns and attitudes, especially those of young men who are considerably more likely than young women or older drivers to get motoring convictions and to become crash-involved. Thus, for example, the special targeting of adolescent males in schools by challenging their attitudes to high speed and other unwanted driving behaviours before they start driving could be worthwhile, as would more precise targeting of male drivers in road safety media campaigns aimed at offence reduction. Further, incentivising convicted male drivers to participate in speed or alcohol awareness programmes should be supported, and consideration given to widening rehabilitative educational opportunities to reach more traffic offenders, especially male offenders.

Secondly, since most vehicle-related offending is perpetrated by men, the implication that women and men are equally culpable in media statements about drivers who break the law is somewhat deceptive. For instance, consider the following statement seen in a British national newspaper in July 2005:

"Two-thirds of drivers regularly break the speed limit, a survey has found. The majority knowingly flout rules of the road and don't fear being caught."

Arguably, such a statement could facilitate further offending among males preferring high speeds who might feel encouraged by an apparent cross-gender consensus for a particular unlawful driving action (or attitude towards it) when, as seen in Table 1 and various self-report studies, this seems not to be the case. 
Thirdly, while the amount of offending between the sexes appears very different, the biggest absolute increases for men and women, young and old, were in the categories of licence, insurance and record-keeping offences. These are often treated as minor victimless offences by the courts but they may have far-reaching implications, as when people are injured or killed by 'hit-and-run' drivers (a growing problem in England and the United States) who cannot be traced through insurance, registration or driver licence records. Strong links have been found between involvement in unlicensed driving and other kinds of car crime and mainstream offending (Broughton, 2006; Rose, 2000), and it is encouraging that considerable financial government support is being lent to a national roll-out in Britain of ANPR (automated number plate recognition) teams and equipment (DfT, 2005) that can be extremely successful in detecting licence and insurance defaulters.

Implications for research:

More research is needed in the area of unlicensed driving to explore the motivating factors for all perpetrators, such as the effects of failing the driving test or being disqualified from driving among young drivers, that may be experienced and coped with differently by men and women. As noted above in the section on demographic changes to the licensed driver pool, it may be that fewer men than women seek retesting, which could help explain the figures in Table 3 suggesting that fewer young male than young female licensed drivers under 21 years are transferring to the over 21years groups.

Another important point, emphasised earlier, is that while there is an overall gender gap in driving styles, not all women's driving styles can be distinguished from men's. More research is needed on the 'ladette' subculture among young women, for example, how attempts to emulate masculine behaviour may manifest in the driving of such women, and what might be needed to prevent escalation of any consequent problem like drink or drug driving among this group and that might be linked with binge drinking. In particular, 'ladettes' do not appear to have been defined by age and could well be older than 20 (which is where published statistics divide the conviction data used), so it would be useful to examine female rates by narrower age bands to see which age groups have increasing conviction rates. Further, it would be good to explore the social and situational determinants of drinking behaviour that might lead 
to drink driving behaviour, such as the marketing and high sales of 'alcopops' targeted at young people and young women in particular, the current trend for fashionable, open modern bars that might encourage drinking events among women, and the expected utility of getting home safely and independently from evenings out offered by car travel.

In this regard too, further attention is merited to the driving behaviour of mid-age women, some of whom seemingly find that their pressured life styles lead to higher levels of traffic offending than usually found among women (Dobson et al, 1999). Such women are not usually cast as a 'traffic crime problem', and it would be ironic to discover that the pressure of contemporary lifestyles, illustrated, for example, by Bost's 'hurried woman' syndrome, was pushing them in that direction.

\section{References}

Aberg, L. and Rimmo, P. (1998). Dimensions of aberrant driver behaviour. Ergonomics, 41(1), 39 - 56.

Anderson, S. and Ingram, D. (2001). Drinking and Driving: Prevalence, Decisionmaking and Attitudes. NFO System Three Social Research. Development Dept Research Programme: Research Findings, 128. Scottish Executive Central Research Unit.

Automobile Association (1999). The Great British Motorist 2000. Basingstoke: AA. Automobile Association (AA) Motoring Trust (2005). Accompanying letter from B. Morris to EuroRAP analysis for N Ireland.

BBC News Magazine (2005). Catching up with boy racers.... 11.1.05. (Geoghegan, T.) http://news.bbc.co.uk/1/hi/magazine/4162431.stm

Blockley, P. and Hartley, L. (1995). Aberrant driving behaviour: errors and violations. Ergonomics, 38(9), 1759 - 1771.

Bost, B. (2001). The Hurried Woman. New York: Vantage Press. Broughton, J. (2006). The correlation between motoring offences and other types of offence. TRL Report 650. Crowthorne: TRL.

Budd, T., Sharp, C. and Mayhew, P. (2005). Offending in England and Wales: First Results from the 2003 Crime and Justice Survey,. HORS 275. London: Home Office. 
Caetano, R. and Clark, C. (2000). Hispanics, blacks and whites driving under the influence of alcohol: results from the 1995 National Alcohol Survey. Accident Analysis and Prevention, 32(1), 57 - 64..

CIECA (Commission Internationale des Examens de Conduite Automobile) (1998). Guide on Driver Licensing 1998. As cited by Automobile Association (1999, 19). Corbett, C. (2000). A typology of drivers' responses to speed cameras: implications for speed limit enforcement and road safety. Psychology, Crime and Law, 6, 305 330.

Corbett, C. (2003). Car Crime. Cullompton: Willan.

Corbett, C. and Simon, F. (1999). The Effects of Speed Cameras: How Drivers Respond. Road Safety Research Report 11. London: DETR.

Corbett, C. and Caramlau, I. (2006). Gender differences in responses to speed cameras: typology findings and implications for road safety. Criminology and Criminal Justice, issue 4.

Daily Mail (2005). Ladette culture blamed for rise in women drink-drivers. 17.3.05, 45. (Nicolson, S.)

Department for Transport (2004). Transport Statistics for Great Britain, 2004 Edition. London: DfT.

Department for Transport (2005) Darling sees new uninsured crackdown in action. News Release, 8.11.05.

Dobson, A., Brown, W., Ball, J., Powers, J. and McFadden, M. (1999). Women drivers' behaviour, socio-demographic characteristics and accidents. Accident Analysis and Prevention, 31(5), 525 - 535.

Dodd, T., Nicholas, S., Povey, D. and Walker, A. (2004). Crime in England and Wales 2003/4. Home Office Statistical Bulletin, 10/04. London: Home Office. ESPAD (2004). The 2003 European School Survey Project on Alcohol and other Drugs. www.espad.org/summary.html

Evans, L. (1991). Traffic Safety and the Driver. New York: van Nostrand Reinhold. Everest, J., Davies, C. and Banks, S. (1990). Roadside Surveys of Drinking and Driving: England and Wales 1990. TRL Report 319. Crowthorne: TRL.

European Commission: Directorate-General Energy and Transport (2004). Statistical Pocket Book: EU Transport in Figures.

http://www.europa.eu.int/comm./dgs/energy_transport/figures/pocketbook/doc/2004/p b2004_part_3_transport.pdf 
Flood-Page, C., Campbell, S., Harrington, V. and Miller, J. (2000). Youth Crime: Findings from the 1998/1999 Youth Lifestyle Survey. London: Home Office.

Forsyth, E. and Silcock, D. (1987). The Association of Traffic Offences with Road Accidents in the Northumbria police area. TOSG Research Report 71. University of Newcastle upon Tyne.

Gottfredson, M. and Hirschi, T. (1990). A General Theory of Crime. Stanford, CA: Stanford University Press.

Graham, J. and Bowling, B. (1995). Young People and Crime. HORS 145, London: Home Office.

Guardian (2006) British girls among most violent in world, WHO survey shows: link to binge-drinking 'ladette' culture feared. 24.1.06, 8. (Honigsbaum, M.). Gusfield, H., Kotarba, J. and Rasmussen, P. (1981). Managing competence: an ethnographic study of drinking-driving and the context of bars. In T. Harford, and L. Gaines (Eds.) Social Drinking Contexts, Research Monograph 7. Washington D.C: US Govt. Printing Office.

Hagan, J., Simpson, J. and Gillis, A. (1979). Modern Criminology: Crime, Criminal Behaviour and its Control. New York: McGraw Hill.

Heidensohn, F. (1996). Women and Crime, $2^{\text {nd }}$ Edition. Basingstoke: Macmillan. Heidensohn, F. (2002). Gender and crime. In M. Maguire, R. Morgan and R. Reiner (Eds.) Oxford Handbook of Criminology, $3^{\text {rd }}$ Edition ( Chapter 15). Oxford: Oxford University Press.

Home Office (2005). Defendants proceeded against at Crown Court/Magistrates'

Courts by Offence, Sex and Result in 2003. Tables S1.1(A) and S2.1(A). www.homeoffice.gov.uk/pdfs04/cs2003vol1pt1.xls

Ingram, D., Lancaster, B and Hope, S. (2001). Recreational Drugs and Driving:

Prevalence Survey. Scottish Executive.

www.scotland.gov.uk/cru/kd01/blue/prevalence-00.htm

Johnson, K. and colleagues (2001). Cautions, Court Proceedings and Sentencing, England and Wales, 2000. HOSB 20/01. London: Home Office.

Junger, M., West, R. and Timman, R. (2001). Crime and risky behavior in traffic: an example of cross-situational consistency. Journal of Research in Crime and Delinquency, 38(4), 439 - 459. 
Junger, M., Terlouw, G-J. and van der Heijden, P. (1995), Crime and accident involvement in young road users. In G. Grayson (Ed.), Behavioural Research in Road Safety $V$ (35 - 54). Crowthorne: TRL

Keane, C., Maxim, P and Teevan, J. (1993). Drinking and driving, self-control and gender: testing a general theory of crime. Journal of Research in Crime and Delinquency, 30(1), 30 - 46.

Knox, D., Turner, B. and Silcock, D. (2003). Research into Unlicensed Driving: Final Report. Road Safety Research Report, 48. London: DfT.

Leaseplan (2001). Leaseplan organises 3d European Drivers Survey. www.leaseplan.be/LP/LP.nsf.e44bc0

Light, R., Nee, C. and Ingham, H. (1993). Car Theft: The Offender's Perspective. HORS 130. London: Home Office.

London Research Centre (1998). Women's Travel in London. London: LRC.

Marsh, P. and Collett, P. (1986). Driving Passion: The Psychology of the Car. London: Cape.

Marsh, P. (2004). Sex Differences in Driving and Insurance Risk. Oxford: Social Issues Research Centre. http://www.sirc.org/publik/driving_risk.shtml Martin, C. and Parker, S. (1995). Folk theories about sex and race differences. Personality and Social Psychology Bulletin, 21, 45 - 57.

Matthews, A. and Richardson, A. (2005). Findings from the 2003 Offending, Crime and Justice Survey: Alcohol-related Crime and Disorder. RDS Findings No. 261. London: Home Office.

Mawby, R. (1981). Sex and crime: The results of a self-report survey. British Journal of Criminology, 31(4).

Maxwell, S. (2001). Negotiations of car use in everyday life. In D. Miller (Ed.), Car Cultures. Oxford: Berg.

Maycock, G., Lockwood, C. and Lester, J. (1991). The Accident Liability of Car Drivers. TRL Report RR315. Crowthorne: Transport Research Laboratory. McKenna, F., Waylen, A. and Burkes, M. (1998). Male and Female Drivers: How Different are they? Basingstoke: AA Foundation for Road Safety Research. Messerschmidt, J. (1993). Masculinities and Crime: Critique and Reconceptualization of Theory. Lanham, MD: Maryland: Rowman and Littlefield. Mizell, L. (1997). Aggressive Driving. Washington: AAA Foundation for Traffic Safety. 
National Statistics Online (2005). Census 2001.

http://www.statistics.gov.uk/census2001/demographic_uk.asp

National Travel Survey Unit (2005). Focus on Personal Travel, 2005 Edition. DfT. London: TSO.

Parker, D., Reason, J., Manstead, A. and Stradling, S. (1995). Driving errors, driving violations and accident involvement. Ergonomics, 38(5), 1036 - 1048.

Prime, J., White, S., Liriano, S. and Patel, K. (2001). Criminal Careers of those born between 1953 and 1978. _HORS Bulletin 4/01. London: Home Office.

Radford, J. and Stanko, B. (1991). Women and children: the contradictions of crime control under patriarchy. In K.Stenson and D. Cowell (Eds.), The Politics of Crime Control. London: Sage.

Reason, J., Manstead, A., Stradling, S., Baxter, J. and Campbell, K. (1990). Errors and violations on the road: a real distinction? Ergonomics, 33(10/11), 1315 - 1332. RoadPeace (2002). Inquests and Road Deaths. London: RoadPeace.

Rose, G. (2000). The Criminal Histories of Serious Traffic Offenders. HORS 206. London: Home Office.

Simon, F. and Corbett, C. (1996). Road traffic offending, stress, age, and accident history among male and female drivers. Ergonomics, 39(5), 757 - 780.

Society of Motor Manufacturers and Traders (1999). Women on the Road: A Study of Female Car Users. London: SMMT.

Storie, V. (1977). Male and Female Car Drivers: Differences Observed in Accidents. Report no. 761. Crowthorne: Transport and Road Research Laboratory.

Stradling, S. and Parker, D. (2001). Influencing Driver Attitudes and Behaviour. Road Safety Research Report, No. 17. London: Dept. for Transport.

Stradling, S., Campbell, M., Allan, I., Gorell, R., Hill, J., Winter, M., TRL Ltd., Hope, S. and NFO System Three Social Research (2003). The speeding driver: who, how and why? Scottish Executive Social Research. Edinburgh: TSO.

Tillmann, W. and Hobbs, G. (1949). The accident-prone automobile driver. American Journal of Psychiatry, 106, 321 - 331.

Tunbridge, R., Keigan, M. and James, F. (2001). The Incidence of Drugs and Alcohol in Road Accident Fatalities. TRL Report 495. Crowthorne: TRL. Vanlaar, W. (2005). Drink driving in Belgium: results from the third and improved roadside survey. Accident Analysis and Prevention, 37(3), 391 - 397.

Voyer, D., Voyer, S. and Bryden, M. (1995). Magnitude of sex differences in spatial 
abilities - a metaanlysis and consideration of critical variables. Psychological Bulletin, 117, 250 - 270.

Waller, P., Elliott, M., Shope, J., Raghunathan, R and Little, R. (2001). Changes in young adult offense and crash patterns over time. Accident Analysis and Prevention, 33(1), 117 - 128.

West, R., Elander, J. and French, D. (1993). Mild social deviance, type-A personality and decision making style as predictors of self-reported driving style and traffic accident risk. British Journal of Psychology, 84, 207 - 219.

Wilson, J.Q. and Herrnstein, R. (1985). Crime and Human Nature. New York: Simon and Schuster.

Zuckerman, M., Eysenck, S., and Eysenck, H. (1978). Sensation seeking in England and America: Cross-cultural, age and sex comparisons. Journal of Consulting and Clinical Psychology, 46, 139 - 149. 
Table 1: Recent trends in the proportion of females found guilty at all courts by type of motoring offence (England and Wales) ${ }^{1}$

\section{Percentage female}

\section{Offence group}

Causing death or bodily harm

Dangerous driving

Driving etc. after consuming alcohol or taking drugs

Careless driving

Accident offences

Unauthorised taking or theft of a motor vehicle

Licence offences

Insurance and record

keeping offences

Vehicle test and condition

offences

Speed limit offences

Neglect of traffic signs and

\section{No. of offences}

$\begin{array}{lcccc}1988 & \mathbf{1 9 9 3} & \mathbf{1 9 9 8} & \mathbf{2 0 0 3} & \mathbf{2 0 0 3} \\ 3 & 5 & 4 & 6 & 371 \\ 1^{2} & 2 & 3 & 4 & 6,788 \\ & & & & \\ 5 & 7 & 9 & 11 & 93,701 \\ 13 & 14 & 15 & 15 & 31,686 \\ 9 & 10 & 12 & 13 & 17,089 \\ & & & & 24,232 \\ 2 & 3 & 4 & 5 & 292,751 \\ 5 & 6 & 8 & 9 & 575,669 \\ & & & & 221,239 \\ 7 & 8 & 11 & 12 & 139,998\end{array}$

\footnotetext{
${ }^{1}$ Data extracted from Table 17 in Supplementary Tables for Motoring Offences England and Wales for 1988 and 1993, and Motoring Offences and Breath Test Statistics for 1998 and 2003. London: Home Office.

${ }^{2}$ Recorded as 'reckless driving' before RTA 1991.
} 
directions and of pedestrian rights

Obstruction, waiting and parking

offences

Lighting and noise offences

Load offences

Offences peculiar to motor cycles

Miscellaneous motoring offences

Total percentage females

$\%$ females in driver licence population
10

13

14

14

28,724

\begin{tabular}{llccl}
15 & 19 & 21 & 24 & 13,243 \\
5 & 7 & 9 & 10 & 10,565 \\
2 & 2 & 3 & 3 & 7,701 \\
4 & 2 & 2 & 3 & 1,996 \\
11 & 18 & 17 & 16 & 66,841 \\
\hline
\end{tabular}

8

38
$8 \quad 11$

12

$1,530,560$

\footnotetext{
${ }^{3}$ All figures supplied by DVLA in 2005.
} 
Table 2: Motoring conviction rates in England and Wales compared by gender and age for 1998 and 2003

\begin{tabular}{|c|c|c|c|c|c|c|c|c|}
\hline & \multicolumn{4}{|c|}{ Males } & \multicolumn{4}{|c|}{ Females } \\
\hline & \multicolumn{2}{|c|}{1998} & \multicolumn{2}{|c|}{2003} & \multicolumn{2}{|c|}{1998} & \multicolumn{2}{|c|}{2003} \\
\hline & $<21$ & $\geq \mathbf{2 1}$ & $<21$ & $\geq 21$ & $<21$ & $\geq 21$ & $<21$ & $\geq 21$ \\
\hline No. full driver licence holders* & 565,364 & $18,151,203$ & 418,572 & $18,560,303$ & 443,904 & $13,458,994$ & 336,862 & $14,455,492$ \\
\hline Total no. convictions** & 238,293 & $1,059,421$ & 258,710 & $1,097,693$ & 15,244 & 139,462 & 14,412 & 168,761 \\
\hline Total no. less licence convictions ${ }^{* * * *}$ & 183,988 & 906,131 & 185,175 & 904,294 & 12,207 & 123,939 & 10,791 & 146,565 \\
\hline Conviction rate per 100 drivers by age & 42.1 & 5.8 & 61.8 & 5.9 & 3.43 & 1.04 & 4.3 & 1.17 \\
\hline Adjusted conviction rate by age $e^{* * * *}$ & 32.5 & 5.0 & 44.2 & 4.87 & 2.75 & 0.92 & 3.2 & 1.01 \\
\hline Conviction rate per 100 drivers & \multicolumn{2}{|c|}{6.93} & \multicolumn{2}{|c|}{7.15} & \multicolumn{2}{|c|}{1.11} & \multicolumn{2}{|c|}{1.24} \\
\hline Adjusted conviction rate ${ }^{* * *}$ & \multicolumn{2}{|c|}{5.82} & \multicolumn{2}{|c|}{5.74} & & & \multicolumn{2}{|c|}{1.06} \\
\hline
\end{tabular}


Table 3: Court Convictions for selected motoring offences by gender and age: \% change between 1998 - 2003

\begin{tabular}{|c|c|c|c|c|c|c|c|}
\hline & & & & & & & \\
\hline & & $<21$ years & old & & 21 years olc & & \\
\hline Offence group & 1998 & 2003 & $\%$ change & 1998 & 2003 & $\%$ change & $\begin{array}{c}\text { Overall \% change } \\
1998-2003\end{array}$ \\
\hline Dangerous driving & 1,729 & 2,246 & +30 & 3,828 & 4,285 & +12 & +18 \\
\hline Driving after alcohol or drugs & 9,405 & 10,947 & +16 & 75,202 & 72,642 & -4 & -1 \\
\hline Accident offences & 3,424 & 3,730 & +9 & 11,762 & 11,137 & -6 & -2 \\
\hline Unauthorised taking or theft of a m/v & 19,735 & 15,159 & -30 & 9,154 & 7,897 & -16 & -25 \\
\hline Licence offences & 54,305 & 73,535 & +35 & 153,290 & 193,399 & +26 & +29 \\
\hline Insurance + record keeping offences & 79,985 & 89,774 & +12 & 369,115 & 415,225 & +13 & +13 \\
\hline Vehicle test and condition offences & 42,293 & 42,916 & +2 & 168,735 & 155,378 & -9 & -6 \\
\hline Speed limit offences & 7,444 & 4,845 & -54 & 125,976 & 110,233 & -14 & -16 \\
\hline Neglect of traffic signs and directions & 3,065 & 3,573 & +17 & 31,820 & 25,488 & -25 & -20 \\
\hline Obstruction, waiting + parking offences & $\underline{226}$ & 166 & -36 & 12,666 & 9,948 & -27 & $\underline{-28}$ \\
\hline Total no. convictions for year: & 238,293 & 258,710 & +9 & $1,059,421$ & $1,097,693$ & +4 & +5 \\
\hline Total convictions omitting licence offences & 183,988 & 185,175 & +1 & 906,131 & 904,294 & $<-1$ & $<-1$ \\
\hline Total no. full licence holders & 565,364 & 418,572 & -35 & $18,151,203$ & $318,560,309$ & $09+2$ & +1 \\
\hline
\end{tabular}

$\underline{\text { Females }}$ 
$<21$ years old

$1998 \quad 2003 \quad \%$ change

\begin{tabular}{llllll}
37 & 45 & $\mathbf{+ 2 2}$ & 148 & 212 & $\mathbf{+ 4 3}$ \\
$\mathbf{6 4 5}$ & 840 & $\mathbf{+ 3 0}$ & 7,864 & 9,272 & $\mathbf{+ 1 8}$ \\
291 & 266 & $\mathbf{- 9}$ & 1,781 & 1,956 & $\mathbf{+ 1 0}$ \\
770 & 707 & $\mathbf{- 9}$ & 372 & 469 & $\mathbf{+ 2 6}$ \\
3,037 & 3,621 & $\mathbf{+ 1 9}$ & 15,523 & 22,196 & $\mathbf{+ 4 3}$ \\
5,167 & 4,828 & $\mathbf{- 7}$ & 51,221 & 65,842 & $\mathbf{+ 2 9}$ \\
2,601 & 2,402 & $\mathbf{- 8}$ & 18,365 & 20,543 & $\mathbf{+ 1 2}$ \\
909 & 647 & $\mathbf{- 4 0}$ & 19,166 & 24,273 & $\mathbf{+ 2 7}$ \\
357 & 224 & $\mathbf{- 5 9}$ & 5,505 & 4,616 & $\mathbf{- 1 9}$ \\
32 & 33 & $\mathbf{+ 3}$ & 3,295 & 3,096 & $\mathbf{- 6}$ \\
\hline
\end{tabular}

Dangerous driving

Driving after alcohol or drugs

Accident offences

Unauthorised taking or theft of a m/v

Licence offences

Insurance + record keeping offences

Vehicle test and condition offences

Speed limit offences

Neglect of traffic signs and directions

Obstruction, waiting + parking offences

Total no. convictions for year:

Total convictions omitting licence offences 12,20

15,244

$14,412 \quad-6$

$10,791-13$

$\begin{array}{lll}139,462 & 168,761 & +21 \\ \mathbf{1 2 3 , 9 3 9} & \mathbf{1 4 6 , 5 6 5} & +\mathbf{1 8}\end{array}$

$\geq 21$ years old

$\begin{array}{llll} & \text { Overall \% change } \\ 1998 & 2003 & \% \text { change } & 1998-2003\end{array}$

Total no. full licence holders

$443,904 \quad 336,862$

$-32$

$+39$

$+19$

$+7$

$+3$

$+39$

$+25$

$+9$

$+24$

$-21$

$-6$

$+18$

$+16$

Total no. full Hicence holders

(1)

$13,458,994 \quad 14,455,492 \quad+7$

$+6$

Conviction data from Table 17 Supplementary Tables to Motoring offences and breath test statistics for 1998 and 2003 , London: Home Office.

Driving licence information supplied by DVLA. 